\title{
Evaluation of pyrene sorption-desorption on tropical soils
}

\author{
Bamidele I. Olu-Owolabi ${ }^{a}$, Paul N. Diagboya ${ }^{a, b, *}$, Kayode O. Adebowale ${ }^{a}$ \\ ${ }^{a}$ Department of Chemistry, University of Ibadan, Ibadan, Nigeria \\ ${ }^{\mathrm{b}}$ National Center for Nanoscience and Technology, Beijing 100190, China
}

\section{A R T I C L E I N F O}

\section{Article history:}

Received 27 November 2013

Received in revised form

26 January 2014

Accepted 31 January 2014

Available online

\section{Keywords:}

Sorption

Pyrene

Tropical soils

Agro-ecological zone

\begin{abstract}
A B S T R A C $T$
Sorption-desorption processes control soil-pollutant interactions. These processes determine the extent of pyrene transport in soils. Understanding sorption characteristics of pyrene is necessary in ascertaining its fate in soil. Laboratory batch experiments were conducted to study the sorptions-desorption of pyrene on eight soils from varying tropical agro-ecological zones (AEZs). The results showed that pyrene sorptions equilibria were attained within $720 \mathrm{~min}$. Solution $\mathrm{pH}$ had a reciprocal effect on pyrene sorptions. Sorption was exothermic and increased with pyrene concentration in solution. The quantities of pyrene sorbed by each soil as well as the hysteresis were proportional to the percentage organic matter, and to some degree, the clay mineralogy. Sorption isotherms showed distributed reactivity involving several linear and non-linear isotherms. The present investigation showed that pyrene is likely to be more available to biota and reach the aquifer faster in low organic matter soils than those with relatively higher organic matter and more so in warmer climes.
\end{abstract}

(C) 2014 Elsevier Ltd. All rights reserved.

\section{Introduction}

Natural polycyclic aromatic hydrocarbons (PAHs) are ubiquitous in the environment; however, their amounts (especially in soils) have been enormously supplemented by human activities resulting in unprecedented soil pollution levels (USEPA, 2007). Soil, the ultimate sink for most pollutants, has aroused widespread concern by scientists and environmentalists because of its importance in global development issues such as food security and global burden of disease (ATSDR, 1995).

The toxicities of PAHs (pyrene, fluorene, naphthalene, Phenanthrene, etc.) are well documented in several biota species (USEPA, 2007), and in some instances it can be amplified by bioaccumulation in the food chain. They have been shown to induce some cancers and genetic defects in humans, and thus PAHs have been classified as priority environmental pollutants by USEPA (USEPA, 2007; An et al., 2010). Hence, understanding the fate of these pollutants in soil is of paramount importance. Although PAHs are among the most intensively studied pollutants (An et al., 2010; Hwang and Cutright, 2002; Teixeira et al., 2011; Sun and Yan, 2007; Ramirez et al., 2001; Haftka et al., 2010), there is dearth of information concerning their fate on tropical sub-Saharan soils especially in Nigeria.

\footnotetext{
* Corresponding author. Department of Chemistry, University of Ibadan, Ibadan, Nigeria. Tel.: +2348038052553.

E-mail address: pauldn2@yahoo.com (P.N. Diagboya).
}

Sorption is a critical process in the control of environmental pollution because the fate of most organic pollutants depends both on the interactions between the soil components and organic pollutant as well as the prevailing conditions of the soil/organic pollutant environment (Hwang et al., 2003). Thus, PAHs will exhibit different fates in different soils formed from different parent materials under different environmental conditions, and this has led to studies concerning their bioavailability and remediation (Hwang and Cutright, 2002; Teixeira et al., 2011; Ramirez et al., 2001). Hence, understanding the sorption-desorption behavior of these contaminants in soils is vital for predicting their fate and transport, and ultimately their bioavailability.

Soils in Nigeria vary extensively in physical and chemical properties in the various agro-ecological zone (AEZs) due to different soil forming parent materials and the prevailing environmental conditions (temperature, moisture, and biota). Considering this diversity of soils in the country, pyrene sorption study using these soils is important in order to obtain technical and environmental safety recommendations for the different soils and climate conditions. Thus, in this study, soils from different AEZs in Nigeria were used.

Pyrene was chosen as a model PAH in this study due to its wide prevalence in soils and the dearth of information on pyrene sorption on Nigerian soils. When in soil, it is subjected to numerous physical, chemical and biological processes that determine its fate. Sorption and desorption are predominant of these, and they determine, to a large extent, the quantity of the organic pollutant 
retained by the soil as well as that leached to the aquifer (Teixeira et al., 2011). Hence, this work was specifically designed to study the sorption and desorption of pyrene on eight soils having varying physicochemical properties in order to understand the effects these properties on pyrene sorption and desorption on soils of African origin. The kinetics and adsorption isotherm models as well as thermodynamics parameters were used to describe the sorption data.

\section{Materials and methods}

\subsection{Soil sampling, pretreatment and characterization}

Eight soil types were obtained from surface soils $(0-30 \mathrm{~cm})$ from eight AEZs in Nigeria - Table $1 \mathrm{a}$ and $\mathrm{b}$ and Fig. 1. Prior to sorption experiments, the soil samples were air-dried, crushed gently and sieved through a 230-mesh size sieve and the fine fractions retained for the study.

The $\mathrm{pH}$ of the soils was determined in milipore ultra-pure water and $1.0 \mathrm{M} \mathrm{KCl}$ (ratio 1:1) (Benton, 2001). Particle size determination was done using the laser particle analyzer (Mastersizer-2000). Organic matter was determined by the Walkley-Black (1934) wet digestion method. Metals (oxides, exchangeable and trace) in the soils were determined using inductively coupled plasma optical emission spectrometry (ICP-OES, Optima 5300DV), except for Cd which was done by inductively coupled plasma mass spectrometry (ICP-MS, Agilent 7500).

\subsection{Pyrene sorption studies}

Pyrene $(100 \mu \mathrm{g} / \mathrm{L})$ was prepared in $20 \% \mathrm{v} / \mathrm{v}$ acetonitrile/milipore ultra-pure water using $0.005 \mathrm{M} \mathrm{CaCl}_{2}$ and $0.01 \mathrm{M} \mathrm{NaN}_{3}$ as background electrolyte and biocide to eliminate microbial degradation, respectively. Sorption experiments were carried by adding $10 \mathrm{~mL}$ of $100 \mu \mathrm{g} / \mathrm{L}$ (except where otherwise stated) pyrene solution into brown vials containing $0.50 \mathrm{~g}$ of the soil sample and then tightly sealed with Teflon lined screw caps. Aluminum foil was used to wrap the vials to minimize possible losses by photochemical decomposition. The vials were equilibrated in the dark by shaking at $100 \mathrm{rpm}$ in a temperature $\left(25^{\circ} \mathrm{C}\right)$ controlled shaker. For the effect of time, the vials were incubated from 10 to $1440 \mathrm{~min}$. Equilibrium studies and effect of temperature were investigated in the concentration range of $20-100 \mu \mathrm{g} / \mathrm{L}$ at $25^{\circ} \mathrm{C}$ and $40^{\circ} \mathrm{C}$. After the equilibrium experiments pyrene desorptions were carried out immediately by thoroughly decanting the incubated solution and replacing with a fresh $20 \% \mathrm{v} / \mathrm{v}$ acetonitrile/milipore ultra-pure water solution containing the same concentration of $\mathrm{CaCl}_{2}$ and $\mathrm{NaN}_{3}$ but no pyrene. These were incubated in similar conditions as above, centrifuged after $1440 \mathrm{~min}$, and pyrene concentration determined. All experiments were done at the ambient soil $\mathrm{pH}$. Control experiments without soil samples were done to account for possible losses due to volatilization and sorption onto the vials walls (and these were found to be negligible). After incubation, the vials were centrifuged at $4000 \mathrm{rpm}$ for $20 \mathrm{~min}$, and the concentration of pyrene in solution determined by Perkin Elmer fluorescence spectroscopy (model LS 55) using the synchronized scan at a wavelength difference $(\Delta \lambda)$ of $36 \mathrm{~nm}$ and scanning from 300 to $400 \mathrm{~nm}$. The synchronous peak at $335 \mathrm{~nm}$ was used to monitor the sorption.

\subsection{Data treatment}

The amounts of pyrene sorbed were calculated from the initial $\left(C_{o}\right)$ and final $\left(C_{e}\right)$ concentrations in solutions after the incubation using the Eq. (1):

$q_{e}=\frac{\left(C_{O}-C_{e}\right) V}{M}$

where $q_{\mathrm{e}}, V$ and $M$ are the amount of pyrene sorbed ( $\left.\mu \mathrm{g} / \mathrm{g}\right)$, volume of the solution $(\mathrm{mL})$ and mass $(\mathrm{g})$ of sample, respectively.

Three adsorption models - Langmuir (1916) (Eq. (2)), Freundlich (1906) (Eq. (3)), and Distributed reactivity model (DRM) (Weber et al., 1992) (Eq. (7)) in their linear forms were employed in describing the adsorption process.

$\frac{C_{e}}{q_{e}}=\frac{1}{Q_{o} b}+\frac{C_{e}}{Q_{o}}$

$\log q_{e}=\log K_{f}+\frac{1}{n} \log C_{e}$

where $Q_{o}(\mu \mathrm{g} / \mathrm{g})$ is the soil maximum adsorption capacity; $b$ the binding energy constant; $K_{f}$ and $n$ are Freundlich isotherm constants; and other parameters are as stated above.

The DRM describes sorption comprised of both linear and nonlinear isotherms. Here, the linear isotherm was represented by Eqs. (4) and (5), and the non-linear isotherm by Eq. (6). A combination of Eqs. (4) and (6) gives the DRM in Eq. (7).

$q_{e}=\left(\sum_{i=1}^{m} x_{i} K_{D}\right) C_{e}=\sum_{i=1}^{m} x_{i} K_{D_{i}} C_{e}$

where $q_{\mathrm{e}}$ and $C_{e}$ are same as above; $K_{D_{i}}$ and $K_{D}$ are the partition coefficient for reaction $i$ expressed on a per mass of component $i$ basis and the mass-averaged partition coefficient for the summed linear components, respectively. For true partitioning processes, Eq. (4) is rearranged to accommodate the mass fraction of the organic matrices

Table 1a

Physico-chemical properties of the soil samples.

\begin{tabular}{|c|c|c|c|c|c|c|}
\hline Soil & $\mathrm{AEZ}^{\mathrm{a}}$ & Sampling coordinate & $\mathrm{pH}$ water & $\mathrm{pH} 1 \mathrm{~N} \mathrm{KCl}$ & $\mathrm{EA}^{\mathrm{c}}$ & $\mathrm{OM}^{\mathrm{d}}(\%)$ \\
\hline Lokoja (LF) & Southern Guinea SV ${ }^{\mathrm{b}}$ & $6^{\circ} 45^{\prime} 00^{\prime \prime} \mathrm{E} ; 7^{\circ} 49^{\prime} 00^{\prime \prime} \mathrm{N}$ & 6.73 & 5.86 & 0.14 & 6.25 \\
\hline Agbor (AG) & Fresh water swamp & $6^{\circ} 11^{\prime} 36^{\prime \prime} \mathrm{E} ; 6^{\circ} 15^{\prime} 06^{\prime \prime} \mathrm{N}$ & 6.29 & 5.39 & 0.10 & 5.26 \\
\hline Gembu (GSF) & Montane & $11^{\circ} 15^{\prime} 00^{\prime \prime} \mathrm{E} ; 6^{\circ} 43^{\prime} 00^{\prime \prime} \mathrm{N}$ & 5.14 & 4.25 & 0.14 & 2.80 \\
\hline $\mathrm{Jos}(\mathrm{JB})$ & Northern Guinea SV ${ }^{\mathrm{b}}$ & $8^{\circ} 52^{\prime} 00^{\prime \prime} \mathrm{E} ; 9^{\circ} 48^{\prime} 00^{\prime \prime} \mathrm{N}$ & 5.17 & 4.08 & 0.44 & 3.57 \\
\hline Port Harcourt (PH) & Mangrove swamp & $6^{\circ} 59^{\prime} 55^{\prime \prime} \mathrm{E} ; 4^{\circ} 47^{\prime} 21^{\prime \prime} \mathrm{N}$ & 7.66 & 7.24 & 0.06 & 5.29 \\
\hline Ibadan (IB) & Moist-lowland/Rainforest & $3^{\circ} 54^{\prime} 00^{\prime \prime} \mathrm{E} ; 7^{\circ} 26^{\prime} 30^{\prime \prime} \mathrm{N}$ & 6.57 & 5.88 & 0.08 & 4.68 \\
\hline Maiduguri (MA) & Sudan SV & $13^{\circ} 09^{\prime} 42^{\prime \prime} \mathrm{E} ; 11^{\circ} 50^{\prime} 36^{\prime \prime} \mathrm{N}$ & 6.67 & 5.21 & 0.02 & 1.67 \\
\hline Monguno (MG) & Sahel SV & $13^{\circ} 36^{\prime} 51^{\prime \prime} \mathrm{E} ; 12^{\circ} 40^{\prime} 14^{\prime \prime} \mathrm{N}$ & 8.40 & 7.59 & 0.12 & 0.18 \\
\hline
\end{tabular}

${ }^{\text {a }}$ AEZ - Agroecological zone.

b SV - Savanna.

c EA - Exchange acidity.

d OM - Organic matter. 
Table $1 \mathrm{~b}$

Physico-chemical properties of the soil samples.

\begin{tabular}{|c|c|c|c|c|c|c|c|c|c|c|c|}
\hline \multirow[t]{2}{*}{ Soil } & \multicolumn{3}{|c|}{ Particle size analysis (\%) } & \multicolumn{2}{|c|}{ Oxides (wt \%) } & \multicolumn{6}{|c|}{ Trace elements/heavy metals (mg/kg) } \\
\hline & Sand $^{\mathrm{a}}$ & Silt $^{\mathrm{b}}$ & Clay $^{\mathrm{c}}$ & $\mathrm{Fe}_{2} \mathrm{O}_{3}$ & $\mathrm{Al}_{2} \mathrm{O}_{3}$ & $\mathrm{Cd}$ & $\mathrm{Cu}$ & $\mathrm{Mn}$ & $\mathrm{Ni}$ & $\mathrm{Pb}$ & $\mathrm{Zn}$ \\
\hline LF & 48.28 & 31.07 & 20.64 & 0.16 & 1.69 & 0.02 & 7.64 & 220.70 & 0.91 & 16.84 & 24.62 \\
\hline AG & 83.80 & 15.44 & 0.76 & 1.54 & 2.78 & 0.11 & 17.46 & 109.70 & 0.00 & 26.78 & 69.53 \\
\hline GSF & 13.88 & 79.75 & 6.36 & 3.90 & 15.75 & 0.00 & 20.15 & 126.30 & 11.22 & 29.52 & 23.24 \\
\hline JB & 42.26 & 57.11 & 0.63 & 3.13 & 9.12 & 1.02 & 33.10 & 134.20 & 9.85 & 119.80 & 165.70 \\
\hline $\mathrm{PH}$ & 68.04 & 30.50 & 1.45 & 1.09 & 2.96 & 0.09 & 5.82 & 228.80 & 4.98 & 8.63 & 20.94 \\
\hline IB & 69.94 & 16.44 & 13.63 & 3.71 & 3.18 & 0.06 & 21.11 & 685.60 & 4.49 & 455.30 & 82.80 \\
\hline MA & 70.44 & 28.89 & 0.67 & 0.99 & 2.23 & 0.10 & 13.60 & 123.50 & 0.00 & 45.85 & 6.57 \\
\hline MG & 82.24 & 17.25 & 0.50 & 0.93 & 1.50 & 0.08 & 14.47 & 112.90 & 0.00 & 17.21 & 6.28 \\
\hline
\end{tabular}

a $\%$ Sand ( $>50 \mathrm{um})$.

b \% Silt (2-50 um).

c \% Clay ( $>2$ um).

$q_{e}=\sum_{i=1}^{m} x_{i} f_{\mathrm{OC}_{i}} K_{\mathrm{OC}_{i}} C_{e}$

where $f_{\mathrm{OC}_{i}}$ and $K_{\mathrm{OC}_{i}}$ are the organic carbon mass fraction and the organic carbon-normalized partition coefficient for the $i$ sorption component, and $\sum x_{i} f_{\mathrm{OC}}$ gives the organic carbon mass fraction $f_{\mathrm{OC}}$ of the bulk soil.

The non-linear isotherms may be modeled using any non-linear model such as the Langmuir and Freundlich. Since the Langmuir isotherm is rarely encountered in soils which are highly heterogeneous, the commonly encountered Freundlich model in its nonlinear form (Eq. (6)) was used.

$q_{e}=\sum_{i=1}^{m}\left(x_{n l}\right)_{i} K_{F_{i}} C_{e}^{n i}$ where $\left(x_{n l}\right)_{i}$ is the mass fraction of the $i$ nonlinear sorption component.

Combining Equations (4) and (6) will give Equation (7).

$q_{e}=x_{i} K_{D} C_{e}+\sum_{i=1}^{m}\left(x_{n l}\right)_{i} K_{F_{i}} C_{e}^{n i}$

where $x_{i}$ is the summed mass fraction of solid phase exhibiting linear sorptions and $\left(x_{n l}\right)_{i}$ is the mass fraction of the $i$ nonlinearly sorption component.

The Lagergren (1898) pseudo-first order (PFO) (Eq. (8)) and pseudo-second order (PSO) (Eq. (9)) models, the Elovich (Eq. (10)), and the Weber and Morris (1963) intra-particle diffusion (Eq. (11)) kinetics models were also used to describe the sorption data.

$\log \left(q_{\mathrm{e}}-q_{\mathrm{t}}\right)=\log q_{\mathrm{e}}-\frac{k_{1}}{2.303} t$

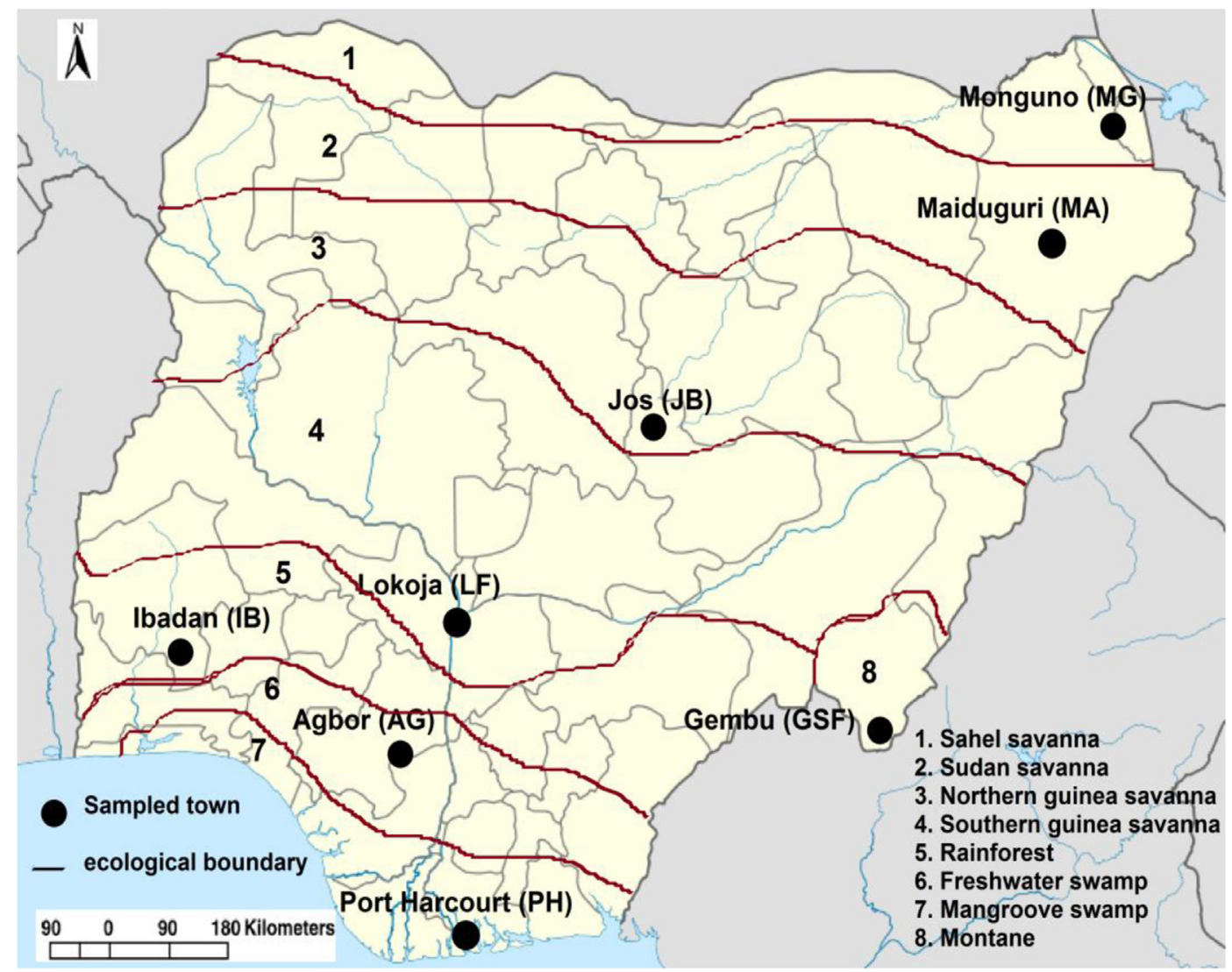

Fig. 1. Map of Nigeria showing the major AEZs and the sampled towns in this study. 
Table 2

The mineralogical composition of the soils determined from the XRD crystallography of soil samples.

\begin{tabular}{|c|c|c|c|c|c|c|c|c|c|c|c|}
\hline \multirow[t]{2}{*}{ Soil } & \multicolumn{11}{|l|}{ Mineral (\%) } \\
\hline & Aragonite & Calcite & Dolomite & Gibbsite & Goethite & Hematite & Illite & Kaolinite & Montmorillonite & Quartz & Siderite \\
\hline LF & 11.77 & 0.29 & 16.21 & - & 18.26 & 1.51 & 15.41 & 11.52 & - & 25.03 & - \\
\hline$A G$ & 2.49 & 5.37 & 8.70 & 23.49 & - & 1.58 & - & 0.68 & - & 57.69 & - \\
\hline GSF & 3.84 & 2.17 & 3.42 & 6.06 & - & 1.87 & - & 3.97 & - & 78.67 & - \\
\hline JB & 7.86 & 1.14 & 11.83 & 57.13 & - & 1.47 & 4.41 & 5.96 & 0.59 & 9.61 & - \\
\hline $\mathrm{PH}$ & 6.53 & 7.40 & 10.69 & 4.61 & - & 0.88 & - & 1.48 & - & 68.41 & - \\
\hline IB & 15.14 & 0.52 & 4.17 & 51.04 & 5.15 & - & - & 2.18 & - & 21.33 & 0.47 \\
\hline MA & 9.89 & 2.37 & 11.72 & 3.48 & - & 2.19 & - & 4.62 & 0.14 & 63.21 & 2.38 \\
\hline MG & 14.38 & 4.48 & 8.19 & 12.67 & - & 2.15 & 36.89 & 1.28 & - & 19.96 & - \\
\hline
\end{tabular}

$\frac{t}{q_{\mathrm{t}}}=\frac{1}{k_{2} q_{\mathrm{e}}^{2}}+\frac{t}{q_{\mathrm{e}}}$

$\mathrm{q}_{\mathrm{t}}=\frac{1}{\beta} \operatorname{In}(\alpha \beta)+\frac{1}{\beta} \operatorname{In}(\mathrm{t})$

$q_{t}=k_{i}\left(t^{1 / 2}\right)+C$

where $q_{\mathrm{e}}$ and $q_{\mathrm{t}}$ are amount sorbed $\left(\mathrm{mg} \mathrm{g}^{-1}\right.$ ) at equilibrium and at time $t$, respectively; and $k_{1}$ and $k_{2}$ are the rate constants $\left(\mathrm{min}^{-1}\right)$ of the PFO and PSO, respectively. The $q_{\mathrm{e}}$ and rate constants were calculated from the slope and intercept of the plots of $\log \left(q_{\mathrm{e}}-q_{\mathrm{t}}\right)$ $v s$. $t$; and $t / q_{\mathrm{t}} v s$. $t$ for PFO and PSO, respectively, $\alpha$ is the initial sorption rate $\left(\mathrm{mg} \mathrm{g}^{-1} \mathrm{~min}^{-1}\right)$ and $\beta$ is the desorption constant $\left(\mathrm{g} \mathrm{mg}^{-1}\right)$ during any one experiment, and $k_{i}\left(\mathrm{mg} / \mathrm{g} / \mathrm{min}^{1 / 2}\right)$ is the rate parameter of the intra-particle diffusion control stage.

The thermodynamic parameters - standard free energy $\left(\Delta G^{\circ}\right)$, enthalpy change $\left(\Delta H^{\circ}\right)$, and entropy change $\left(\Delta S^{\circ}\right)$ were calculated using Eqs. (12)-(15) (Olu-Owolabi et al., 2012).

$K_{C}=\frac{C_{\mathrm{ads}}}{C_{e}}$

$\log K_{C}=-\frac{\Delta H^{\circ}}{2.303 R T}+\frac{\Delta S^{\circ}}{2.303 R}$

$\Delta G^{\circ}=-R T \ln K_{C}$

$\Delta S^{\circ}=\frac{\left(\Delta H^{\circ}-\Delta G^{\circ}\right)}{T}$

where $C_{\text {ads }}$ and $C_{e}$ are the amount of sorbate sorbed and the amount remaining in solution after equilibrium, and $\left(K_{C}\right)$ is equilibrium constant.

\section{Results and discussion}

\subsection{Soil properties}

Table 1 ( $a$ and $b$ ) show the sampling locations and physicochemical characteristics of all samples. The soils' physicochemical properties were compared to the reference soil of moist lowlands in Nigeria (Fagbami and Shogunle, 1995). The pH values were mainly neutral (6.0-7.5) except for GSF and JB which were acidic (5.0-5.5) and MG which was alkaline (8.0-9.0). Soil organic matter (SOM) values were high except for GSF and MA which were described as medium, and MG which is very low. LF, AG and PH had the highest SOM contents. Metal and metal oxides varied with AEZ: GSF and JB had the highest percent of Fe and Al oxides, while heavy and trace metals in these studied soils were within concentration ranges found in soils (Sparks, 2003). The mineralogical compositions (Table 2) determined from the XRD crystallography indicated that the major minerals in the soils are aragonite, calcite, dolomite, gibbsite, goethite, hematite, illite, kaolinite, montmorillonite, quartz, and siderite. Quartz was the most common mineral. The percentages of quartz mineral were over $55 \%$ for AG, GSF, PH, and MA soils, while those of LF, JB, IB, and MG were between 10 and $25 \%$. Another common mineral is the $\mathrm{Al}$ oxide mineral - gibbsite. Gibbsite percentage compositions vary widely from major in JB and IB, to minor in other soils. Iron oxide/hydroxides minerals (goethite and hematite) were found to be minor minerals. Montmorillonite, a 2:1 expansive clay mineral, was found in JB and MA; while Illite, another 2:1 expansive clay mineral, was present in LF, JB, and MG. The presence of Kaolinite, a 1:1 in-expansive clay mineral, as well as the carbonate minerals (aragonite, calcite, siderite, and dolomite) are common features of these soils. The variations in the physico-chemical properties of these soils are understandable bearing in mind the different ambient environmental conditions (vegetation, temperature, topography, rainfall, climate, soil forming minerals, biotic influence, etc) associated with these AEZs.

\subsection{Adsorption study}

\subsubsection{Effect of time and kinetics of pyrene sorption}

The effect of time on pyrene sorptions on all eight soils was investigated to determine the time it takes to attain equilibrium. Results (Fig. 2) showed that pyrene sorptions attained equilibrium

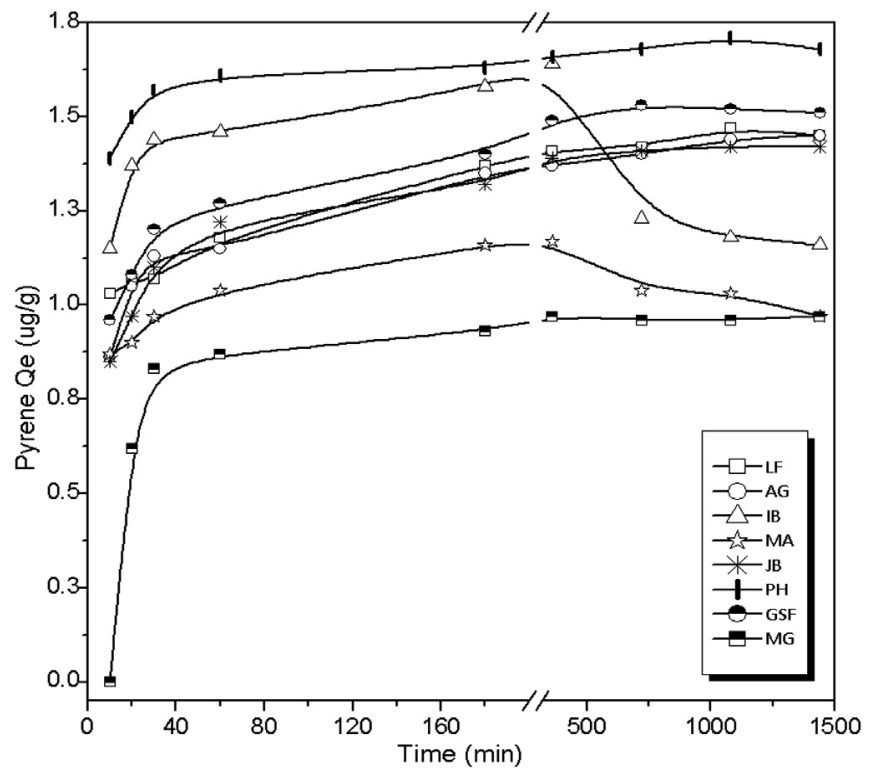

Fig. 2. Effect of time on the sorption of pyrene. 
within 180 min for the soils except for MA and IB soils which attained equilibrium within $720 \mathrm{~min}$. MA and IB soils showed an initial high sorption of pyrene between the 60th and 360th minutes, followed by a cycle of sorptions and desorptions until equilibrium was attained. Attainment of equilibrium meant that no significant sorption and/or desorption of pyrene were recorded after the equilibrium point. Similar observation have been reported (Teixeira et al., 2009; Cottin and Merlin, 2007; Teixeira et al., 2011).

The data generated from the effect of time experiments were fitted into four kinetics models: Lagergren pseudo-first and second order, Elovich and intra-particle diffusion kinetics models (Table 3). These models were used to describe pyrene sorptions as well as predict the mechanisms involved in the removal of pyrene from solution.

Table 3 shows the kinetics models parameters of the four models for the soils. Comparison of the correlation coefficients $\left(r^{2}\right)$ and the estimated model sorption capacity $\left(q_{\mathrm{e}}\right)$ values of the Lagergren pseudo-first and second-order kinetics showed that the pyrene sorptions data were better described by the pseudo-second order kinetics model with $r^{2}$ and $q_{\mathrm{e}}$ values closer to unity (0.9991.000 ) and the experimental values, respectively. The small deviations observed in the pseudo-second order kinetics model $q_{\mathrm{e}}$ values have been attributed to the uncertainties inherent in obtaining the calculated $q_{\mathrm{e}}$ values.

The estimated $q_{\mathrm{e}}$ values from the Elovich kinetics model showed that the sorptions could be explained by this model. The Elovich model which originated from chemical reaction kinetics suggested that since the curves did not pass through the origin (SM Fig. 2), there is some degree of boundary layer control between the pyrene molecules in solution and the soils' surface active sorption sites. This boundary layer control is assumed to be related to the rate controlling mechanism and involves $\pi-\pi$ interactions between the pyrene molecules in solution and active sorption sites at the soil surface.

The Weber-Morris (1963) intra-particle diffusion model parameters were calculated (Table 3 ) to determine whether film diffusion or intraparticle diffusion is the rate limiting step. The model suggested that if the sorption mechanism is via intraparticle diffusion then a plot of $q_{\mathrm{t}}$ versus $t^{1 / 2}$ will be linear; and intraparticle diffusion is the sole rate-limiting step when such a plot passes through the origin. When the sorption process is controlled by more than one mechanism, then a plot of $q_{\mathrm{t}}$ versus $t^{1 / 2}$ will be multi-linear. Given the multi-linear nature (Fig. 3) of the plot for pyrene sorption on these soils, it is proposed that sorption occurred in three phases. The initial steep phase (Fig. 3-a) represented surface diffusion, the second less steep phase (Fig. 3-b) represented a gradual sorption of pyrene where intra-particle diffusion within the pores is rate-limiting, and the third phase

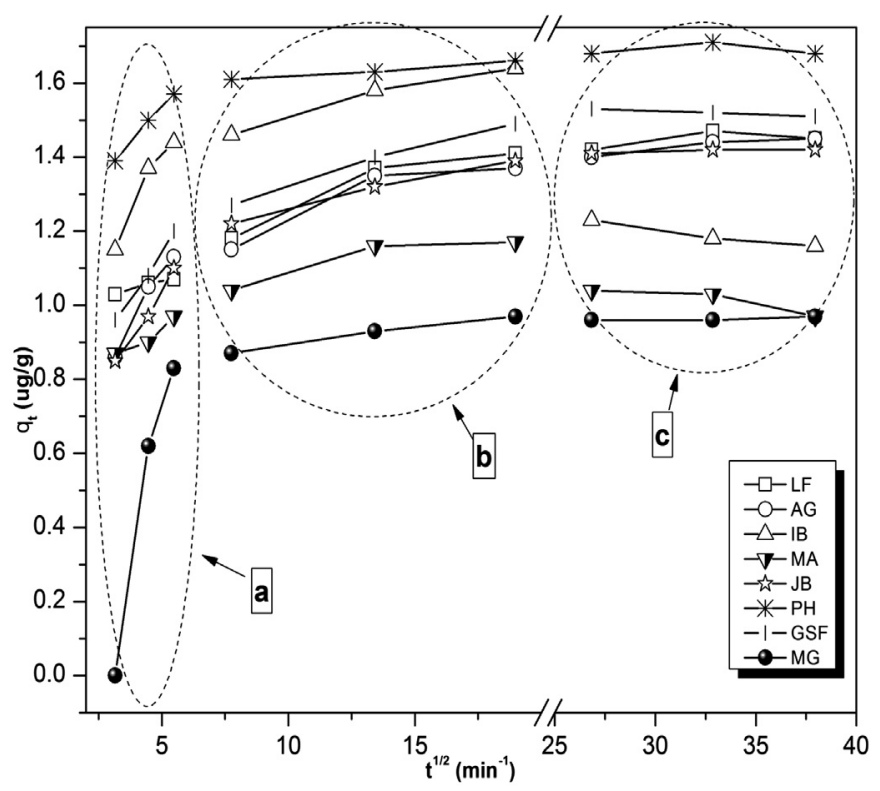

Fig. 3. Intra-particle diffusion model plots for pyrene sorption.

(Fig. 3-c) where equilibrium had been achieved. Since the plot did not pass through the origin, intra-particle diffusion was not the only rate-limiting step. There were three processes controlling pyrene sorption rate but only one predominates at any particular time phase. The values of the intra-particle diffusion model constants are shown in Table 3 . The $C\left(\mu \mathrm{g} \mathrm{g}^{-1}\right)$ values indicate the thickness of the boundary layer which was observed to be very small for these soils; and these low $C$ values suggested that surface diffusion plays less role as the rate-limiting step in the overall sorption process.

\subsubsection{Effect of $p H$ on pyrene sorption}

Sorption behaviors of PAHs can be significantly influenced by soil properties. It has been recognized that $\mathrm{pH}$ is an important factor affecting pyrene sorption in soils because of the influence of solution $\mathrm{pH}$ on soil properties especially the nature of the surface sorption sites (An et al., 2010). In this study, soil solution pH values have been varied between 3 and 9 in order to investigate the extent to which pyrene sorption is dependent on solution $\mathrm{pH}$.

Results (Fig. 4) showed that irrespective of the soils' physicochemical characteristics the pyrene sorption trend for these soils were similar. Pyrene sorptions were significantly affected as soil solution $\mathrm{pH}$ changed. Pyrene sorptions were relatively high at low

Table 3

Calculated kinetics model parameters.

\begin{tabular}{|c|c|c|c|c|c|c|c|c|c|}
\hline \multirow[t]{2}{*}{ Kinetics model } & \multirow[t]{2}{*}{ Model parameters } & \multicolumn{8}{|c|}{ Soil samples } \\
\hline & & LF & AG & IB & MA & JB & $\mathrm{PH}$ & GSF & MG \\
\hline \multirow[t]{3}{*}{ Pseudo-first-order } & $q_{\mathrm{e}}\left(\mu \mathrm{g} \mathrm{g}^{-1}\right)$ & 0.318 & 0.873 & 0.221 & 0.594 & 0.285 & 0.244 & 0.330 & 0.275 \\
\hline & $K_{1}\left(\min ^{-1}\right)$ & 0.000 & 0.000 & 0.000 & 0.000 & 0.002 & 0.000 & 0.000 & 0.000 \\
\hline & $r^{2}$ & 0.783 & 0.659 & 0.159 & 0.004 & 0.822 & 0.654 & 0.674 & 0.453 \\
\hline \multirow[t]{3}{*}{ Pseudo-second-order } & $q_{\mathrm{e}}\left(\mu \mathrm{g} \mathrm{g}^{-1}\right)$ & 1.46 & 1.46 & 1.16 & 0.99 & 1.43 & 1.70 & 1.52 & 0.99 \\
\hline & $K_{2}\left(\mathrm{~g} \mu \mathrm{g}^{-1} \mathrm{~min}^{-1}\right)$ & 0.06 & 0.05 & 0.03 & 0.07 & 0.07 & 0.15 & 0.08 & 0.23 \\
\hline & $r^{2}$ & 0.999 & 0.999 & 0.995 & 0.997 & 1.000 & 0.999 & 0.999 & 0.999 \\
\hline \multirow[t]{3}{*}{ Elovich } & $q_{e}\left(\mu \mathrm{g} \mathrm{g}^{-1}\right)$ & 1.43 & 1.42 & 1.34 & 1.06 & 1.41 & 1.69 & 1.43 & 1.00 \\
\hline & $\beta$ & 10.309 & 9.259 & 71.429 & 34.483 & 9.009 & 19.231 & 9.009 & 7.634 \\
\hline & $r^{2}$ & 0.948 & 0.933 & 0.020 & 0.272 & 0.914 & 0.854 & 0.933 & 0.580 \\
\hline \multirow[t]{3}{*}{ Intra-particle diffusion } & $C\left(\mu \mathrm{g} \mathrm{g}^{-1}\right)$ & 1.062 & 1.013 & 1.449 & 0.981 & 1.004 & 1.495 & 1.095 & 0.545 \\
\hline & $K_{\mathrm{id}}$ & 0.012 & 0.013 & 0.005 & 0.002 & 0.013 & 0.006 & 0.013 & 0.014 \\
\hline & $r^{2}$ & 0.805 & 0.756 & 0.153 & 0.075 & 0.707 & 0.654 & 0.735 & 0.363 \\
\hline
\end{tabular}


solution $\mathrm{pH}$ but then decreased with the increasing $\mathrm{pH}$ values of the soil solution system until around $\mathrm{pH} 6.0$ where little changes in the amount of pyrene sorbed were observed. Soil organic matter contents played significant role the sorption; the higher the organic matter content, the higher the pyrene sorption. Lower sorptions were observed at higher $\mathrm{pH}$ values especially close to neutrality: a reflection of the true pyrene sorption character of these soils in the normal environment since the natural ambient $\mathrm{pH}$ values of these soils are close to neutral. Similar findings have been reported in literature (An et al., 2010).

The increased sorption of pyrene at low pH values was attributed to the fact that at such $\mathrm{pH}$ values, there is reduced polarity of charged surface sites on the soil organic matter and clay minerals resulting from the displacement of charged atoms by protons in solution (reduced ionization and increased association). The soils then become more hydrophobic with increased affinity for hydrophobic compounds like pyrene, thus the observed high pyrene sorption. However, with elevation in soil solution $\mathrm{pH}$ values, the competition for charged sites on the soil organic matter and clay minerals by protons in solution drops correspondingly due to increased ionization and dissociation resulting in increased polarity and reduced hydrophobicity; and hence, the acquired affinity for hydrophobic compounds is lost resulting in the reduced pyrene sorption observed.

\subsubsection{Dynamics of pyrene sorption}

Equilibrium pyrene sorption data (Fig. 5a-d and SM Fig. 2 e-h) showed that increasing the solution concentration of pyrene resulted in higher sorption of pyrene from solution. Teixeira et al. (2011) and An et al. (2010) have reported similar findings for Brazilian soils. The increase in pyrene sorption with increase in solution concentration of pyrene was attributed to the fact that when the soil external surface film and internal pores transports of pyrene are equal, the trans-boundary movement of pyrene will not be significantly permissible; however, increasing concentration will re-initiate the trans-boundary movement of pyrene and sorption will be concentration dependent. Also, increasing the concentration of non-polar organic sorptive in solution also led to increased occurrence of multi-layer adsorption due to $\pi-\pi$ interactions. Hence, higher pyrene concentration led to higher sorption. Pyrene

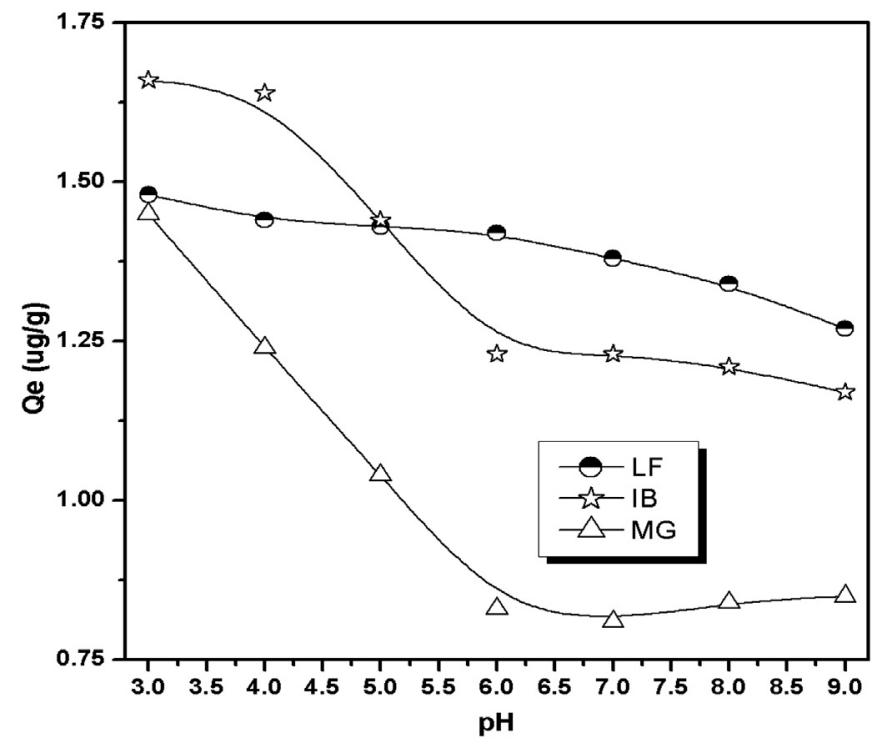

Fig. 4. Effect of solution $\mathrm{pH}$ on pyrene sorption. sorption trend for these soils were observed to be dependent on the quantity of organic matter, and to some degree, the clay mineralogy of each soil: $\mathrm{PH}>\mathrm{JB} \geq \mathrm{GSF}>\mathrm{LF} \geq \mathrm{AG}>\mathrm{IB}>\mathrm{MA} \geq \mathrm{MA}$. Comparing the pyrene sorptions of soils with the highest organic matter $(\mathrm{PH}$, LF, AG, and IB), it was observed that the sorption was not proportional to the organic matter contents but followed a trend $(\mathrm{PH}>\mathrm{AG}>\mathrm{IB}>\mathrm{LF})$ that could be linked to the degree of hydrophobic organic matter in the soil. This degree was predicted based on the source of organic matter in the soil. Soils obtained from the southerly part of Nigeria are believed to have more hydrophobic organic matter content because of the rich deposit of biota remains from these forest regions. Hence, this sorption trend was attributed to the polarity of soil organic matter (Guo et al., 2010; Site, 2001; Huang et al., 2003); the lower the polarity, the higher the affinity for hydrophobic organic pollutants. Hence, sorption of hydrophobic organic chemicals by soils and sediments is driven by hydrophobic interactions.

Fig. $5 \mathrm{a}-\mathrm{d}$ (and SM Fig. $2 \mathrm{e}-\mathrm{h}$ ) also showed that increase in temperature reduced the pyrene sorptions on these soils; thus indicating that the removal of pyrene from solution was exothermic. The reduced sorption resulting from increase in temperature was also an indication that the pyrene sorption was via weak hydrophobic forces (requiring low sorption heat) of interaction between the soil sorption sites and the pyrene molecules. Similar reduction in organic pollutants sorption as temperature increased has been reported (Abdel-Salam and Burk, 2009; Shu et al., 2010). This reduced pyrene sorption was attributed to the fact that pyrene solubility increases with temperature, and this subsequently increases its mobility. This implies that the thin surface film of pyrene molecules on the soil sorption sites will redissolve in solution and move away from these sites, leading to the reduced sorption.

Desorption studies on these soils (Fig. 6 and SM Fig. 3) also supported the observation of the contribution of organic matter in pyrene sorption on these soils. Soils with relatively high contents of organic matter showed low pyrene desorption when compared to those of lower organic matter contents and thus, desorption followed a reverse trend as the sorptions. Hence, as in sorption, desorptions could be predicted on the bases of the organic matter contents in the soils. Site (2001) has reported similar results of high hysteresis for high organic matter containing soils. Again, comparing the desorptions from soils with the highest organic matter (PH, LF, AG, and IB) showed that these soils desorbed the lest quantities of pyrene confirming the role of organic matter in pyrene sorption. The desorption trend ( $\mathrm{LF}>\mathrm{IB}>\mathrm{AG} \geq \mathrm{PH}$ ) was in agreement with the earlier observation that polarity of the soil organic matter determined the extent of hydrophobic interactions in pyrene sorption.

The thermodynamic parameters $\Delta G^{\circ}, \Delta H^{\circ}$, and $\Delta S^{\circ}$ (Table 4) were calculated from the equilibrium sorption data. The $\Delta H^{\circ}$ and $\Delta S^{\circ}$ values were in the range of -67.51 to $63.70 \mathrm{~kJ} \mathrm{~mol}^{-1}$ and -0.21 to $0.23 \mathrm{~kJ} \mathrm{~mol}^{-1}$, respectively. The $\Delta H^{\circ}$ and $\Delta S^{\circ}$ values were negative with the exception of $\mathrm{PH}, \mathrm{GSF}$, and MG soils. The negative $\Delta H^{\circ}$ values conformed to the experimentally observed exothermic nature of the pyrene sorption process, while negative $\Delta S^{\circ}$ values indicated a decrease in the randomness at the solidliquid interface as the pyrene sorption process proceeded towards equilibrium due to ordered accumulation of the pyrene molecules on the soil. The size of the $\Delta H^{\circ}$ can give clue on the type of interaction(s) associated with the sorption process. In this study, the values of $\Delta H^{\circ}$ were compatible with energy strengths associated with weak hydrophobic forces such as the Van-der Waals and $\pi-\pi$ interactions which are common means of interaction for hydrophobic organic compounds with little or no polar groups. 

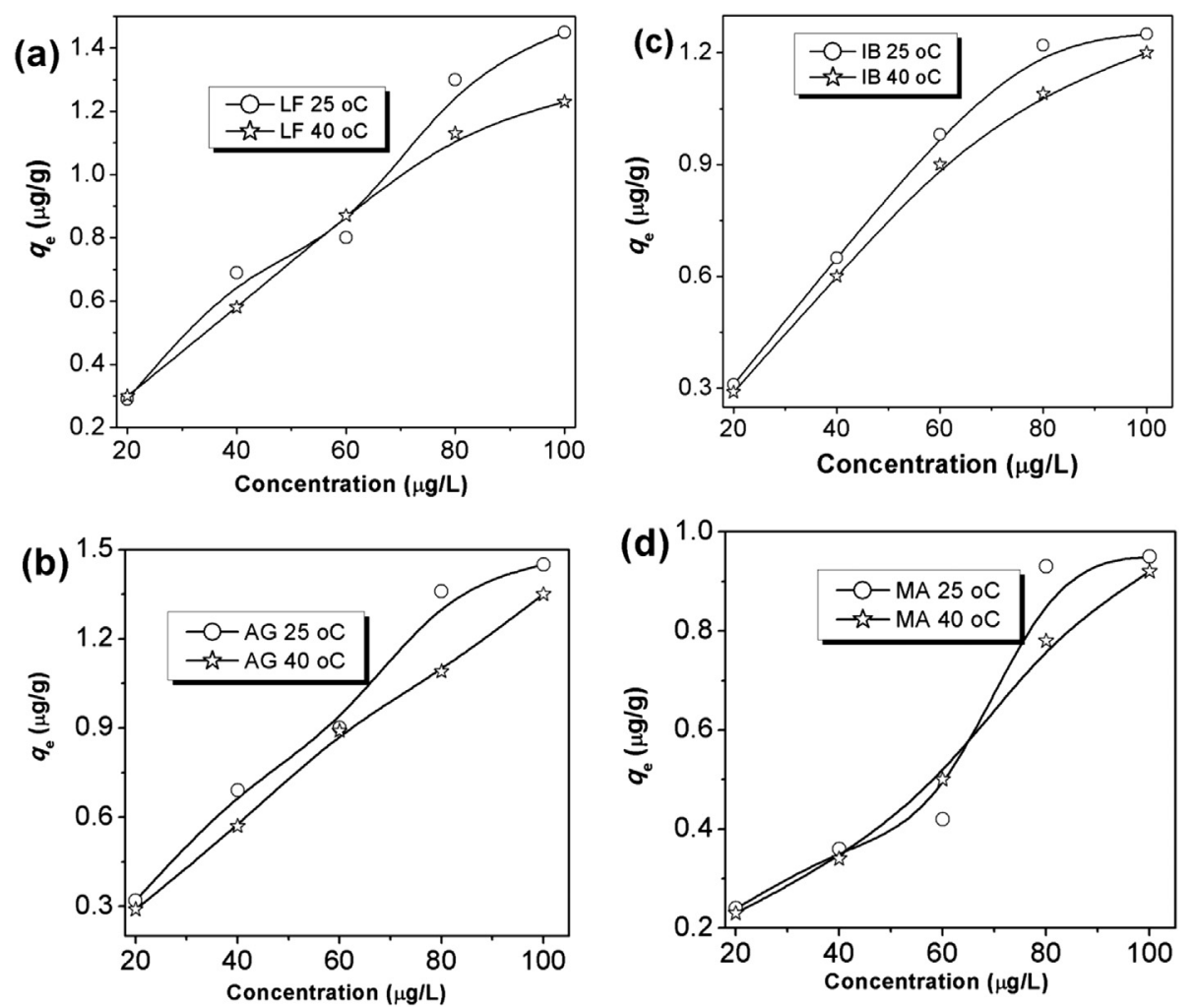

Fig. 5. Pyrene sorption variation as solution pyrene concentration and temperature changes for (a) LF, (b) AG, (c) IB, and (d) MA soils samples.
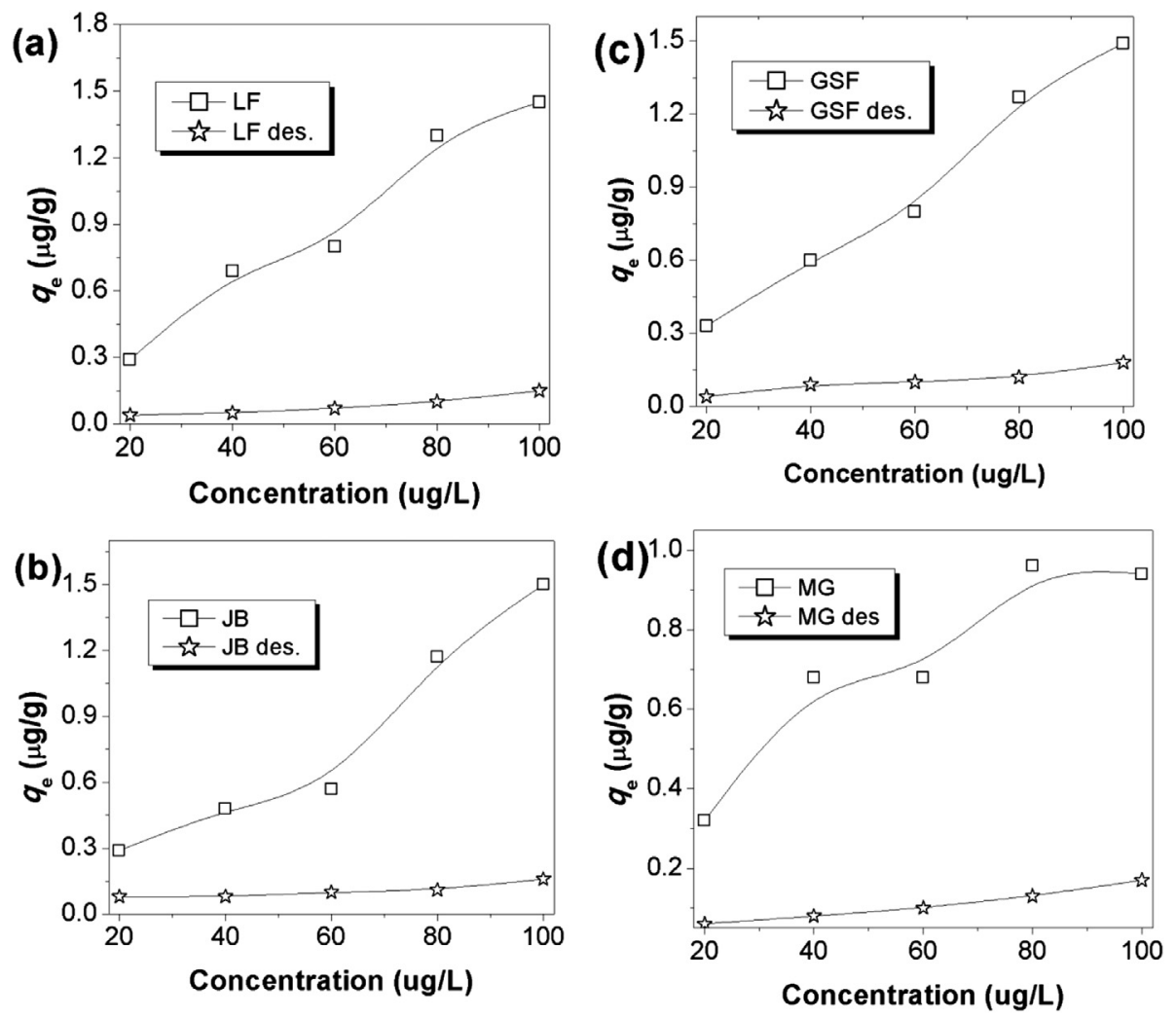

Fig. 6. Pyrene sorption and desorption curves for (a) LF, (b) JB, (c) GSF, and (d) MG soils samples. 
Table 4

Thermodynamic parameters for pyrene sorption on the whole soils.

\begin{tabular}{|c|c|c|c|c|}
\hline \multirow[t]{2}{*}{ Soil } & \multirow{2}{*}{$\frac{\Delta H^{\circ}}{\left(\mathrm{kJ} \mathrm{mol}^{-1}\right)}$} & \multirow{2}{*}{$\frac{\Delta S^{\circ}}{\left(\mathrm{kJ} \mathrm{mol}{ }^{-1} \mathrm{~K}^{-1}\right)}$} & \multicolumn{2}{|c|}{$\Delta G^{\circ}\left(\mathrm{kJ} \mathrm{mol}{ }^{-1}\right)$} \\
\hline & & & $298 \mathrm{~K}$ & $313 \mathrm{~K}$ \\
\hline LF & -67.51 & -0.21 & -6.30 & -3.22 \\
\hline$A G$ & -17.42 & -0.04 & -5.06 & -4.44 \\
\hline IB & -40.53 & -0.12 & -4.96 & -3.17 \\
\hline MA & -30.96 & -0.07 & -9.79 & -8.72 \\
\hline JB & -65.44 & -0.19 & -8.80 & -5.95 \\
\hline $\mathrm{PH}$ & 10.86 & 0.06 & -8.42 & -9.39 \\
\hline GSF & 63.70 & 0.23 & -5.95 & -9.45 \\
\hline MG & 27.40 & 0.10 & -3.85 & -5.42 \\
\hline
\end{tabular}

Negative $\Delta G^{\circ}$ values were observed for the studied soils, an indication that the sorption of pyrene on these soils was feasible and spontaneous with sorptive forces which were strong enough to break any initial sorption barrier and shift the reaction towards the sorption of pyrene onto the surface sorption sites on these soils. With the exceptions of $\mathrm{PH}, \mathrm{GSF}$, and MG, the decrease in $\Delta G^{\circ}$ values with increase in temperature shows that the sorption is not favorable at high temperatures because of increased kinetic energy and higher pyrene solubility and consequently desorption of pyrene from the soils sorption sites.

Exceptions to the exothermic sorption of pyrene on these soils $\mathrm{PH}, \mathrm{GSF}$, and MG - could be attributed to inherent errors associated with the linear model calculations of the thermodynamic parameters which become significant when dealing with low energy sorption surfaces (Unuabonah et al., 2008).

\subsubsection{Sorption isotherm models}

The equilibrium sorption data of pyrene on the soils at $25{ }^{\circ} \mathrm{C}$ were fitted to different sorption isotherm models. Table 5 showed the values of the isotherm parameters for both models. It was observed that neither the Langmuir nor the Freundlich could fit suitably and be used to explain the sorption of pyrene on these soils. This is attributed to the fact that most natural soils are intrinsically heterogeneous and variable in composition even at the microscopic scale. Though neither the Langmuir nor Freundlich suitably fit the sorption data, the small values of the Freundlich parameter $n$ of less than 1 (ranging from 0.58 to 0.77 ) indicated that the bulk of the isotherms involved in pyrene sorptions tended towards non-linearity (Table 5). $n$ values may be regarded as an index of surface site energy distribution (Weber et al., 1992), where small $n$ values represent sorption on predominantly heterogeneous sorption sites. This is in agreement with our earlier predicted mechanisms that pyrene sorptions on these soils are governed by

Table 5

Pyrene sorption isotherm parameters for the Langmuir, Freundlich, and Distributed Reactivity Models (DRM).

\begin{tabular}{|c|c|c|c|c|c|c|c|c|c|}
\hline \multirow[t]{2}{*}{ Soil } & \multicolumn{3}{|c|}{$\begin{array}{l}\text { Langmuir sorption } \\
\text { model }\end{array}$} & \multicolumn{4}{|c|}{ Freundlich sorption model } & \multicolumn{2}{|c|}{$\begin{array}{l}\text { Distributed } \\
\text { reactivity } \\
\text { model (DRM) }\end{array}$} \\
\hline & $\begin{array}{l}Q_{0} \\
(\mathrm{mg} / \mathrm{g})\end{array}$ & $b$ & $r^{2}$ & $q_{\mathrm{e}}(\mathrm{mg} / \mathrm{g})$ & $n$ & $K_{f}$ & $r^{2}$ & $\begin{array}{l}q_{\mathrm{T}(\mathrm{l}+\mathrm{nl})^{\mathrm{a}}} \\
(\mathrm{mg} / \mathrm{g})\end{array}$ & $r^{2}$ \\
\hline LF & 2.22 & 0.05 & 0.340 & 1.32 & 0.58 & 0.21 & 0.528 & 1.45 & 1.000 \\
\hline AG & 2.19 & 0.08 & 0.639 & 1.57 & 0.60 & 0.24 & 0.676 & 1.45 & 0.992 \\
\hline IB & 1.73 & 0.09 & 0.908 & 1.60 & 0.59 & 0.20 & 0.805 & 1.25 & 0.984 \\
\hline MA & 1.42 & 0.02 & 0.225 & 0.80 & 0.65 & 0.07 & 0.651 & 0.95 & 0.988 \\
\hline $\mathrm{JB}$ & 0.90 & 0.19 & 0.400 & 0.83 & 0.64 & 0.12 & 0.449 & 1.5 & 0.983 \\
\hline $\mathrm{PH}$ & 1.15 & 0.13 & 0.346 & 0.96 & 0.77 & 0.11 & 0.439 & 1.58 & 0.994 \\
\hline GSF & 2.12 & 0.06 & 0.419 & 1.27 & 0.65 & 0.17 & 0.822 & 1.49 & 0.957 \\
\hline MG & 1.05 & 0.15 & 0.948 & 0.99 & 0.32 & 0.29 & 0.672 & 0.94 & 0.931 \\
\hline
\end{tabular}

${ }^{\mathrm{a}} q_{\mathrm{T}(\mathrm{l}+\mathrm{nl})}(\mathrm{mg} / \mathrm{g})$ - total linear (l) and non-linear (nl) sorption. sorption onto specific sorption sites, partitioning onto the voids of soil components such as the clay minerals, as well as by weak hydrophobic forces of interaction between soil sorption surfaces and the pyrene molecules.

Pyrene sorption on these soils was therefore assumed to be characterized by multiple reaction phenomena, and the equilibrium sorption data was then fitted to the distributed reactivity model (DRM). The model assumes that there are several individual linear and non-linear isotherms that make up the final soil isotherm. These individual isotherms were treated as a composite of the general linear and general non-linear isotherms experienced in the soil for a particular sorption process.

The results of the fittings of the equilibrium sorption data of pyrene at $25{ }^{\circ} \mathrm{C}$ are shown in Table 5 . It was observed that the sorption of pyrene fitted the distributed reactivity model (DRM) with correlation coefficients $\left(r^{2}\right)$ in the range of $0.957-1.000$. These results support the assumption that pyrene sorptions on these soils are characterized by multiple reaction phenomena composed of several linear and non-linear isotherms of the types in Equations (3) and (5).

\section{Conclusion}

The sorption results for these soils provided evidence for understanding the relationship between the sorption behavior of pyrene and the physicochemical composition of these soils. Results showed that pyrene sorptions equilibria were fast and usually attained within $720 \mathrm{~min}$. The rate determining step of pyrene sorptions was the boundary layer control between the pyrene molecules in solution and the soils' surface active sorption sites. Solution $\mathrm{pH}$ had a reciprocal effect on pyrene sorptions. The quantity of pyrene sorbed by each is proportional to the quantity of organic matter, and to some degree, the clay mineralogy of each soil. Sorption was exothermic and enthalpy values indicated that weak hydrophobic forces, such as the Van-der Waals and $\pi-\pi$ interactions, were involved in the sorptions interaction. The sorption was characterized as multiple reaction phenomena composed of several linear and non-linear isotherms. Hence, in the environment, pyrene will be more available to biota and reach the aquifer faster in low organic matter soils than those with relatively higher organic matter and more so in warmer temperatures.

\section{Acknowledgments}

We acknowledge the supports of the World Academy of Sciences (TWAS), Trieste Italy; the Chinese Academy of Sciences (CAS), China for the award of CAS-TWAS Postgraduate Fellowship (FR number: 3240255024) to P. N. Diagboya; and the Chief S.L. Edu/Chevron research grant.

\section{Appendix A. Supplementary data}

Supplementary data related to this article can be found at http:// dx.doi.org/10.1016/j.jenvman.2014.01.048.

\section{References}

Abdel-Salam, M., Burk, R.C., 2009. Thermodynamics and kinetics studies of pentachlorophenol adsorption from aqueous solutions by multi-walled carbon nanotubes. Water Air Soil Pollut. 210, 101-111.

An, C., Huang, G., Yu, H., Wei, J., Chen, W., Li, G., 2010. Effect of short-chain organic acids and $\mathrm{pH}$ on the behaviors of pyrene in soil-water system. Chemosphere 81, 1423-1429.

ATSDR, 1995. Toxicological Profile for Polycyclic Aromatic Hydrocarbons (PAHs). http://www.atsdr.cdc.gov/toxprofiles/tp69.pdf.

Benton Jr., J.J., 2001. Laboratory Guide for Conducting Soil Tests and Plant Analysis. CRC Press, New York. 
Cottin, C.N., Merlin, G., 2007. Study of pyrene biodegradation capacity in two types of solid media. Sci. Total Environ. 380, 116-123.

Fagbami, A.A., Shogunle, E.A.A., 1995. Nigeria: Reference Soil of the Moist Lowlands Near Ife (Oshun State). Soil Brief Nigeria 3. University of Ibadan, and International Soil Reference and Information Centre, Wageningen, p. 3.

Freundlich, H.M.F., 1906. Über die adsorption in lösungen. Z. Phys. Chem. 57A, 385470.

Guo, X., Luo, L., Ma, Y., Zhang, S., 2010. Sorption of polycyclic aromatic hydrocarbons on particulate organic matters. J. Hazard Mater. 173, 130-136.

Haftka, J.J.H., Govers, H.A.J., Parsons, J.R., 2010. Influence of temperature and origin of dissolved organic matter on the partitioning behavior of polycyclic aromatic hydrocarbons. Environ. Sci. Pollut. Res. 17, 1070-1079.

Hwang, S., Cutright, T.J., 2002. Biodegradability of aged pyrene and phenanthrene in a natural soil. Chemosphere 47, 891-899.

Hwang, S., Ramirez, N., Cutright, T.J., Ju, L.K., 2003. The role of soil properties in pyrene sorption and desorption. Water Air Soil Pollut.. http://dx.doi.org/ 10.1023/A:1022863015709.

Lagergren, S., 1898. Zur theorie der sogenannten adsorption gelöster stoffe. Kungliga svenska vetenskapsakademiens. Handlingar 24, 1-39.

Langmuir, I., 1916. The constitution and fundamental properties of solids and liquids. J. Am. Chem. Soc. 38, 2221-2295.

Olu-Owolabi, B.I., Diagboya, P.N., Ebaddan, W.C., 2012. Mechanism of $\mathrm{Pb}^{2+}$ removal from aqueous solution using a nonliving moss biomass. Chem. Eng. J. 195-196, $270-275$.

Ramirez, N., Cutright, T., Ju, L.K., 2001. Pyrene biodegradation in aqueous solutions and soil slurries by mycobacterium PYR-1 and enriched consortium. Chemosphere 44, 1079-1086.
Shu, Y., Li, L., Zhang, Q., Wu, H., 2010. Equilibrium, kinetics and thermodynamic studies for sorption of chlorobenzenes on CTMAB modified bentonite and kaolinite. J. Hazard Mater. 173, 47-53.

Site, A.D., 2001. Factors affecting sorption of organic compounds in natural sorbent/ water systems and sorption coefficients for selected pollutants. A Review. J. Phys. Chem. Ref. Data 30, 187-439.

Sparks, D.L., 2003. Environmental Soil Chemistry. Academic Press, San Diego, p. 16. Sun, H.W., Yan, Q.S., 2007. Influence of Fenton oxidation on soil organic matter and its sorption and desorption of pyrene. J. Hazard Mater. 144, 164-170.

Teixeira, S.C.G., Marques, M.R., Canela, M.C., Ziolli, R.L., Pérez, D.V., 2009. Study of pyrene adsorption on Brazilian soils. Rev. Chim. (Bucuresti) 60, 6.

Teixeira, S.C.G., Ziolli, R.L., Marques, M.R.C., Pérez, D.V., 2011. Study of pyrene adsorption on two Brazilian soils. Water Air Soil Pollut. 219, 297-301.

U.S.E.P.A, 2007. Treatment Technologies for Site Cleanup: Annual Status Report (ASR), twelfth ed. (EPA 542-R-07-012).

Unuabonah, E.I., Adebowale, K.O., Olu-Owolabi, B.I., Yang, L.Z., Kong, L.X., 2008. Adsorption of $\mathrm{Pb}(\mathrm{II})$ and $\mathrm{Cd}(\mathrm{II})$ from aqueous solutions onto sodium tetraboratemodified kaolinite clay: equilibrium and thermodynamic studies. Hydrometallurgy 93, 1-9.

Walkley, A., Black, I.A., 1934. An examination of the degtjareff method for soil organic matter and a proposed modification of the chromic acid titration method. Soil. Sci. 37, 29-38.

Weber, W.J., Morris, J.C., 1963. Kinetics of adsorption on carbon from solutions. J. Sanit. Eng. Div. Am. Soc. Civ. Eng. 89, 31-60.

Weber, W.J.J., McGinley, P.M., Katz, L.E., 1992. A distributed reactivity model for sorption by soils and sediments. 1. Conceptual basis and equilibrium assessments. Environ. Sci. Technol. 26, 1955-1962. 